\title{
Minireviews
}

\section{Immune Responses Alter Taste Perceptions: Immunomodulatory Drugs Shape Taste Signals during Treatments}

\author{
D Anthony Y. Huang \\ Department of Anatomy and Center for Integrated Research in Cognitive and Neural Science, Southern Illinois University School \\ of Medicine, Carbondale, Illinois
}

Received July 3, 2019; accepted October 8, 2019

\begin{abstract}
Considering that nutrients are required in health and diseases, the detection and ingestion of food to meet the requirements is attributable to the sense of taste. Altered taste sensations lead to a decreased appetite, which is usually one of the frequent causes of malnutrition in patients with diseases. Ongoing taste research has identified a variety of drug pathways that cause changes in taste perceptions in cancer, increasing our understanding of taste disturbances attributable to aberrant mechanisms of taste sensation. The evidence discussed in this review, which addresses the implications of innate immune responses in the modulation of taste functions, focuses on the adverse effects on taste transmission from taste buds by immune modulators responsible for alterations in the perceived intensity of some taste modalities. Another factor, damage to taste progenitor cells that directly results in local
\end{abstract}

effects on taste buds, must also be considered in relation to taste disturbances in patients with cancer. Recent discoveries discussed have provided new insights into the pathophysiology of taste dysfunctions associated with the specific treatments.

\section{SIGNIFICANCE STATEMENT}

The paradigm that taste signals transmitted to the brain are determined only by tastant-mediated activation via taste receptors has been challenged by the immune modification of taste transmission through drugs during the processing of gustatory information in taste buds. This article reports the findings in a model system (mouse taste buds) that explain the basis for the taste dysfunctions in patients with cancer that has long been observed but never understood.

\section{Introduction}

Taste disorders such as ageusia (lack of taste), hypogeusia, and dysgeusia, particularly the inability to detect basic tastes, can have a substantial negative impact on general health and quality of life by affecting appetite and influencing food choices. Several clinical studies have reported that about $15 \%-55 \%$ of patients with cancer suffer from changes in taste perceptions (Kumar and Narang, 2011; Berking et al., 2014; Murtaza et al., 2017). The cause has been shown to be an innate immune response that appears to be a common factor in many diseases associated with gustatory dysfunction. Taste cells, which respond to the potential pathogen-associated molecular patterns (PAMPs), i.e., converted bacterial structures, are equipped with various immune signaling molecules,

This work was supported by American Association of Anatomists Fellows Grant Award Program [Grant AAA-3419] and Southern Illinois University School of Medicine [Grant RSG507060] to A.Y.H. Conflict of interest: The author declares no competing financial interests.

https://doi.org/10.1124/jpet.119.261297. especially those associated with the innate defense response. Several laboratories have reported that taste cells express PAMP recognition receptors, such as Toll-like receptors (TLRs) and their corresponding adaptor proteins, including cytokines, chemokines, and their receptors (Wang et al., 2007, 2009; Cohn et al., 2010; Feng et al., 2012; Huang and $\mathrm{Wu}, 2016)$. Furthermore, studies in recent years have described an emerging role for receptors, corresponding to that of pathogens and proinflammatory cytokines, in the subsequent regulation of taste bud functions (Wang et al., 2007, 2009; Shi et al., 2012; Feng et al., 2015). In rodentbased model studies, the innate immune response was not only critical for maintaining the structural integrity of taste buds (Kim et al., 2012; Feng et al., 2014) but also correlated with circumstances within taste buds, whereby taste signal transmissions were altered during the processing of gustatory information (Huang and $\mathrm{Wu}, 2016$ ). Although the causes of taste disturbances are multifactorial, defective peripheral taste signaling resulting in stasis taste sensations is a common pathophysiological contributor to taste disorders.

ABBREVIATIONS: CGRP, calcitonin gene-related peptide; GABA, $\gamma$-aminobutyric acid; GPCR, G protein-coupled receptor; 5-HT, serotonin; IFN, interferon; IL, interleukin; PAMP, pathogen-associated molecular pattern; PLC, phospholipase C; SP, substance P; TLR, Toll-like receptor; TNF, tumor necrosis factor; TRPM5, transient receptor potential cation channel subfamily M member 5; TRPV1, transient receptor potential vanilloid. 
The division of the sense of taste into several basic taste modalities in human (sweet, sour, bitter, salty, umami, and possibly fatty) yields nutritive information, influences palatability, and aids avoidance of harmful substances from the environment. Taste buds, the peripheral taste organs, are small clusters of specialized epithelial cells on the tongue and in the oral cavity. Initiation of taste sensations is coordinated through activation of taste receptors expressed on specific taste cells, which release transmitters during gustatory stimulation to stimulate primary afferent sensory fibers that carry the gustatory information to the brain (Finger et al., 2005; Huang et al., 2007; Taruno et al., 2013). Although the sense of taste serves the critical function of guiding dietary selection and avoiding toxins and indigestible materials, intriguingly, taste perceptions may be altered by medications (Heath et al., 2006; Kumar and Narang, 2011; Berking et al., 2014; Murtaza et al., 2017; Frampton and Basset-Séguin, 2018). Indeed, human taste thresholds are altered by selective serotonin reuptake inhibitors such as Prozac (Heath et al., 2006; PDR Staff, 2010). Furthermore, our previous study that investigated the taste signal transmission in support of the rodent research demonstrated that serotonin (5-HT) provides negative paracrine feedback on intercellular signaling (Huang et al., 2009). Conceivably, altered taste perceptions seen in patients with affective disorders may reflect an actual change in the peripheral taste organs in the gustatory system. The concept that the functions of taste buds are responsible for establishing taste thresholds in both health and disease is beginning to be elucidated.

\section{Intercellular Interactions within Taste Buds}

In humans, there are about 5000 taste buds in the oral cavity. They are located mostly on the dorsal surface of the tongue but also on the palate and epiglottis. Their apical tips directly contact the external environment in the oral cavity via taste pores. In addition to about 100 elongated taste cells extending from the base of the taste bud to its apex, there are a few taste progenitor cells at the base of the taste bud. An identification scheme that integrates the characteristics of ultrastructures and expression of functional proteins involved in taste transduction recognizes four morphotypes: type I, type II, type III cells, and basal cells, sometimes termed type IV. Initiation of taste sensations consists of a highly complex set of cell-to-cell interactions within taste buds, via transmitters, prior to propagation of signals to the brain (Finger et al., 2005; Herness and Zhao, 2009; Huang et al., 2007, 2009). For additional details regarding their roles in taste, there are several excellent reviews on this topic (Chaudhari and Roper, 2010; Roper and Chaudhari, 2017).

Type I cells comprise more than half the total number of cells in a taste bud and enwrap adjacent taste cells with extended cytoplasmic processes. Type I cells, with glial-like functions, express a surface-bound enzyme, ecto-ATPase, to eliminate the extracellular ATP (Finger et al., 2005; Bartel et al., 2006). As well, type I cells possess ion channels involved in $\mathrm{K}^{+}$homeostasis within the internal environment of taste buds (Dvoryanchikov et al., 2009). Type I cells responsible for salt taste remain to be confirmed by future studies, but Vandenbeuch et al. (2008) have reported $\mathrm{Na}^{+}$transduction mechanisms in type I cells that are implicated in salt taste. Moreover, type I cells synthesize and express the enzyme of $\gamma$-aminobutyric acid (GABA) (Dvoryanchikov et al., 2011; Huang et al., 2011a) and secrete GABA during peptidergic stimulations (Huang and $\mathrm{Wu}, 2018$ ).

Type II cells, approximately one-third of cells in a taste bud, express G protein-coupled receptors (GPCRs) for taste as well as downstream effectors such as phospholipase C (PLC) $\beta 2$. GPCRs consist of heterodimers of the taste receptor type 1 family, i.e., T1R1, T1R2, and T1R3, for sweet and umami compounds, and the taste receptor type 2 family (T2Rs) for bitter compounds. Conceivably, type II cells respond to a variety of taste compounds including sweet, bitter, and umami stimuli (Yang et al., 2000; Medler et al., 2003; Clapp et al., 2006; DeFazio et al., 2006; Tomchik et al., 2007; Huang et al., 2009; Deshpande et al., 2010; Yoshida et al., 2010; Roper and Chaudhari, 2017). Additionally, the expression of transient receptor potential cation channel subfamily M member 5 (TRPM5), essential for initiating taste signal transmission, is found on type II cells (Talavera et al., 2008; Ishimaru and Matsunami 2009; Huang and Roper, 2010). Upon gustatory stimulation, type II cells secrete ATP via gap junction hemichannels (Huang et al., 2007;Huang and Roper, 2010 Romanov et al., 2007) or voltage-gated ion channels (Taruno et al., 2013). Furthermore, ATP excites gustatory sensory afferent fibers through P2X receptors (Finger et al., 2005; Huang et al., 2011b; Vandenbeuch et al., 2015) and, acting as a paracrine transmitter, ATP also excites adjacent type III taste cells (Huang et al., 2009).

Type III cells, about $20 \%$ of cells in a taste buds, form the synaptic contacts with peripheral nerve terminals (Yang et al., 2000; Yee et al., 2001; Huang and Wu, 2015). A sensation scheme that integrates responses to acid (sour) taste stimuli as well as carbonated solutions (Huang et al., 2006, 2008b; Chandrashekar et al., 2009; Chang et al., 2010) and high concentrations of KCl (Huang et al., 2007; Oka et al., 2013) generally indicates that type III cells are responsible for signaling these sensations. Transmitters secreted from type III cells, including 5-HT (Huang et al., 2007), norepinephrine (NE) (Huang et al., 2008a), and GABA (Huang et al., 2011a), mediate inhibitory feedback to type II cells during the processing of gustatory information in taste buds (Huang et al., 2009; Dvoryanchikov et al., 2011; Roper and Chaudhari, 2017). Given the importance of signal transmission in taste buds, the modulation of gustatory information in peripheral sensory organs is attributable to cell-to-cell communication through purinergic, aminergic, and GABAergic signaling.

\section{The Significance of Identifying the Transmitters in Taste Buds}

One of the striking mechanisms of taste sensations is the intercellular communication that is generally associated with taste transmitters. Taste sensations require initial compilations of cell-to-cell interactions prior to transmission of a coherent output to excite primary gustatory afferent fibers and the resulting dispatch of signals to the brain (Herness and Zhao, 2009; Huang et al., 2009; Jaber et al., 2014). This information processing involves cell-to-cell communication via transmitters such as ATP, 5-HT, NE, and GABA within the taste bud. Cell-to-cell signaling is basic to other sensory organs, most notably the retina (Rogers et al., 2005; Palacios-Prado et al., 2009; 
Wurm et al., 2010), but also the carotid body (Xu et al., 2003; Nurse, 2005; Eyzaguirre, 2007) and elsewhere. The importance of knowing the transmitters involved in taste receptions cannot be underestimated. Current strategies to modify taste use as a basis molecules that 1) act on taste GPCRs to enhance sweetness and depress bitterness (Xu et al., 2004; Clapp et al., 2006; Delay et al., 2006; Chaudhari et al., 2009; Kinnamon and Vandenbeuch 2009; Treesukosol et al., 2009; Ohkuri et al., 2009) or that 2) act on effectors immediately downstream of taste GPCRs, such as TRPM5 (de Araujo et al., 2008; Devantier et al., 2008; Talavera et al., 2008; Ishimaru and Matsunami 2009; Long et al., 2010) and inositol 1,4,5-trisphosphate receptor (IP3R) (Hisatsune et al., 2007). Taste modification by manipulation of transmission within the taste bud has seen many new developments, controversies, and clarifications in the past decade. The implications for diet selection (such as during aging), compliance in taking medications (namely, by suppressing drug bitterness), and as a result enhancement of the quality of life are just beginning to be investigated.

\section{Chemesthetic Regulations of Taste Sensations}

Generally speaking, somatosensory branches of the trigeminal ( $\mathrm{CN} \mathrm{V})$, glossopharyngeal ( $\mathrm{CN}$ IX), and vagus $(\mathrm{CN}$ $\mathrm{X})$ cranial nerves innervate the epithelium in which taste buds are located. The terminals of these somatosensory fibers often surround taste buds, indicating the close association of the gustatory and somatosensory systems. Chemesthesis is the general chemical sensitivity of the skin and mucus membranes in the oronasal cavities and is perceived as pungency, irritation, or heat. Chemesthetic activators, such as capsaicin and a variety of other strong oral irritants, act on these populations of sensory fibers via transient receptor potential vanilloid 1 (TRPV1) receptors (Ishida et al., 2002; Roper, 2014).

The notion that taste sensations consists only of gustatory information generated by taste stimuli themselves in taste buds may be too simplistic. Environmental changes in the mouth, such as temperature, may alter taste sensations. For instance, the temperature highly influences the pungency of foods and beverages, so that their acidity and, for beverages, their carbonation are altered when they are consumed. Considering that peripheral sensory nerve terminals that have ability to release stored transmitters [e.g., calcitonin gene-related peptide (CGRP) and substance $\mathrm{P}(\mathrm{SP})$ ] onto taste cells, this modulation was interpreted as being produced indirectly by the axon reflex (Wang et al., 1995; Ishida et al., 2002; Simon et al., 2003). Furthermore, using electrophysiology (Simon et al., 2003), $\mathrm{Ca}^{2+}$ imaging (Huang and $\mathrm{Wu}, 2015$, 2018), and psychophysical testing (Kapaun and Dando, 2017), several studies investigating polymodal nociceptors in taste buds support the notion that oral nociceptive inputs are modulators of gustatory transmission, and their contributions influence the perceived intensity of some taste modalities. These findings extended the results of a previous study, which showed that the CGRP- and SP-immunoreactive nerve fibers innervating the epithelium containing taste buds coexpress TRPV1 in vallate taste papillae (Ishida et al., 2002). Recent imaging results reported that their stored transmitters, CGRP and SP, acting on taste cells via their corresponding receptors elicit secretion of signaling molecules and, as a result, shape taste signals within taste buds during gustatory stimulations (Huang and $\mathrm{Wu}, 2015,2018)$. Collectively, one of the brilliant features of the peptidergic action within taste buds is the important chemesthetic regulation of taste signal transmission that, theoretically, may relate to the processing of the gustatory information. In sum, sensations experienced in the mouth affect the taste signal transmission, and thus influence food choices.

Parenthetically, recent studies reported a specific subset of TRPV1-expressing neurons that preferentially coexpress TLR7 (Helley et al., 2015) and that are equipped with diverse intracellular molecules responsible for the immune response (Kim et al., 2011). Conceivably, despite CGRP and/or SP shaping of taste signals during the processing of gustatory information in taste buds, the innate immune response may also regulate taste responses indirectly via peptidergic modulations within taste buds. Although intriguing, this hypothesis needs further investigation. Figure 1 summarizes this postulated scenario in the schematic taste bud.

\section{Mechanisms of Immunity within Taste Buds}

Clinically, one of the striking features of diseases such as upper respiratory viral infection, oral cavity infection, and viral hepatitis is a loss of taste ability that is characterized by increased detection and recognition thresholds for various taste stimuli, such as bitter, sour, salty, and sweet compounds (Henkin et al., 1972, 1975; Goodspeed et al., 1987; Graham et al., 1995; Weiffenbach et al., 1995; Cullen and Leopold, 1999; Gomez et al., 2004). Furthermore, patients with such cancers as basal cell carcinoma express similar complaints about taste impairments (Kumar and Narang, 2011; Berking et al., 2014; Yang et al., 2015; Frampton and Basset-Séguin, 2018). Notably, the inflammatory state of advanced diseases appears to play a role in infectious diseases as well as in cancers associated with taste disturbances (Kumar and Narang, 2011; Murtaza et al., 2017). Despite the importance/severity of the clinical state generally associated with taste dysfunctions, little information has been generated regarding the interaction between immunity and taste.

Taste bud cells, which face great challenges in the oral cavity from potential PAMPs such as lipopolysaccharide, a major component of the outer membrane of bacteria, are equipped with various inflammatory mechanisms associated with the innate immune response (Wang et al., 2007, 2009; Shi et al., 2012; Feng et al., 2015). By detecting the presence of TLRs in taste buds using reverse transcription-polymerase chain reaction and immunohistochemistry, previous findings have shown that TLRs 2, 3, 4, and 7 are expressed in a subset of taste cells (Wang et al., 2009; Huang and Wu, 2016). Stimulating TLRs produces proinflammatory cytokines and chemokines, such as interferon (IFN)- $\alpha$, IFN- $\gamma$, IFN-inducible protein-10 (IP-10), interleukin (IL)-6, IL-10, IL-12, or tumor necrosis factor- $\alpha$ (TNF) (Hemmi et al., 2002; Oda and Kitano, 2006; Kawai and Akira, 2007; Brikos and O’Neill, 2008; Hwang et al., 2014). Furthermore, recent studies reported the cascade of cytokine signaling pathways, such as changes in gene expression, that affect taste bud functions. For instance, activation of taste tissue via the IFN- $\gamma$ receptor (IFNGR1), most probably on subsets of type II and type III cells, results in the phosphorylation of some transcription factors and the expression of IFN-inducible genes. As a result, the process of apoptosis is facilitated, as well as the increase of the number of 


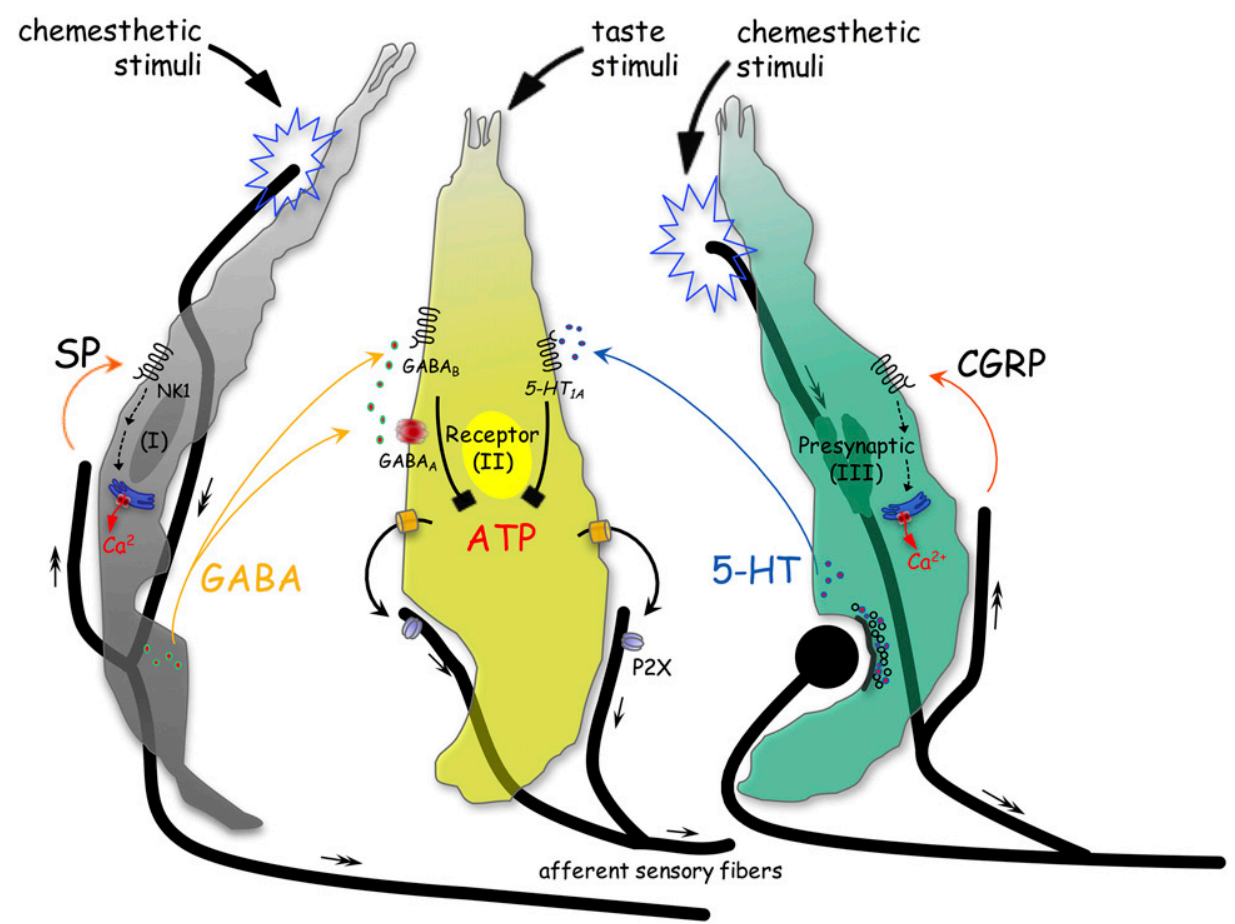

Fig. 1. Cell-to-cell communication via transmitters released from cells inside taste buds participates in the processing of gustatory information. Type I (I) cells secrete GABA, type II (II) cells secrete ATP, and type III (III) cells secrete 5-HT. ATP is the final output, which activates gustatory afferent fibers that propagate taste signals (small arrows) centrally (Finger et al., 2005; Huang et al., 2007; Jaber et al., 2014; Vandenbeuch et al., 2015). Chemesthesis-taste interactions are elucidated in the schematic diagram. Peripheral afferent fibers propagating sensory signals centrally (double-headed arrows) are activated by chemesthetic stimuli, such as capsaicin, and release SP and/or CGRP (orange curved arrows). CGRP acts on taste cells via CGRP receptors, most probably on type III cells. CGRP, as an inhibitory transmitter, shapes peripheral taste signals via serotonergic signaling (blue curved arrow) (Huang and Wu, 2015), i.e., theoretical modification of gustatory information in taste buds. Moreover, SP acts on type I cells via SP receptors (NK1 receptors), elicits increase of intracellular $\mathrm{Ca}^{2+}$ transients, and as a result evokes secretion of GABA, which reduces peripheral taste signals through a GABAergic signaling cascade (yellow curved arrows) (Huang and Wu, 2018). Collectively, an interaction scheme that interprets the peptidergic actions within taste buds recognizes an important chemesthetic modification of the gustatory information processed in taste buds. Image reproduced with permission from A.Y. Huang.

dead taste cells. These results suggest that interferon-induced cell death in taste buds may cause abnormal taste cell turnover (Wang et al., 2007, 2009; Cohn et al., 2010; Feng et al., 2012). Conversely, Feng et al. (2014) reported that a specific subset of taste cells secretes IL-10, which is consistent with a role in maintaining structural integrity of taste buds via an increase in the number of taste bud cells as well as the size of taste buds. Collectively, the immune response triggered by TLR activation contributes to taste dysfunction, which is associated with significant reductions in the sizes of peripheral taste organs, taste buds, and numbers of T1R- and T2R-expressing cells per taste buds (Murtaza et al., 2017).

\section{Immunomodulatory Drugs, Such as Imiquimod, Shape the Signal Outputs That Taste Buds Transmit to the Brain}

A medication sometimes causes changes in the body's ability to recognize taste sensations (Kumar and Narang, 2011; Berking et al., 2014; Yang et al., 2015; Frampton and Basset-Séguin, 2018). Roughly, drugs may stimulate interactions between the innate immune response and the taste signal transmission, and thus modulate taste. Imiquimod, acting as an immune response modifier approved by the US Food and Drug Administration (FDA) for the treatment of basal cell carcinoma, acts on tumor cells via TLR7 to promote $\mathrm{T}$ cell-mediated apoptosis, and thus induces the production of interferon and other cytokines (Imbertson et al., 1998; Miller et al., 1999; Dahl, 2000; Schön et al., 2003; Heil et al., 2003, 2004; Kim et al., 2011). Strictly speaking, TLR7, a pattern-recognition receptor that recognizes PAMPs, initiates the innate immune response (Heil et al., 2004; Krieg and Vollmer, 2007; Kim et al., 2011; Hwang et al., 2014 ), which results in the production of proinflammatory cytokines, including IFN- $\alpha$ and TNF- $\alpha$ (Hemmi et al., 2002; Schön et al., 2003). Feng et al. (2012) have recently confirmed that taste cells express high levels of TNF- $\alpha$. Indeed, during cancer treatments, imiquimod initiates proinflammatory cytokine pathways associated with loss of taste perceptions, as reported by Kumar and Narang (2011).

By using chimeric receptor approaches and immunohistochemistry, previous researchers have reported that TLR7, instead of localizing on the cell surface like regular TLRs, is completely localized in such intracellular compartments as endosomes or lysosomes (Lee et al., 2003; Akira and Takeda, 2004; Nishiya et al., 2005; Oda and Kitano, 2006; Kim et al., 2011). Imiquimod would enter the cells through the cell-surface membrane to access TLR7, which is localized in intracellular compartments, and to target PLC or other intracellular molecules (Cocco et al., 2001a,b; Suh et al., 2008; Grinberg et al., 2009). As in the mechanism of the brain-immune communication pathway (Quan and Banks, 2007), if imiquimod was able to enter the circulation directly and reach the gustatory epithelia containing taste buds, where small molecules could penetrate into the taste bud from the mucosa to influence activities of taste cells, several taste bud cell types, including type II and type III cells that have been shown to express TLR7 (Wang et al., 2009), would therefore be able to respond directly (Huang and $\mathrm{Wu}, 2016$ ). Alternatively, proinflammatory cytokines and other soluble mediators could enter the circulation and 
reach the gustatory epithelia containing taste buds. Remarkably, despite the results of the previous study which showed the robust imiquimod-elicited $\mathrm{Ca}^{2+}$ responses seen in the dorsal root ganglion neurons (Kim et al., 2011), our group recently confirmed that imiquimod elicited PLCdependent $\mathrm{Ca}^{2+}$ transients in the taste cells, most probably in type III cells (Huang and Wu, 2016), which is evidence for direct effects of systemic imiquimod administration in taste buds. Unexpectedly, considering that TLR7 is found in type II and type III cells, the direct activation is improbable because loxoribine, an agonist of TLR7, failed to trigger $\mathrm{Ca}^{2+}$ transients in taste cells. Therefore, the mechanisms of imiquimod-elicited $\mathrm{Ca}^{2+}$ signaling cascade remain an enigma, but imiquimod appears to activate PLC either directly or indirectly by binding to a second messenger. Furthermore, using $\mathrm{Ca}^{2+}$ imaging with cellular biosensors to test whether imiquimod shapes the final taste signal output transmitted from taste buds to the brain, our laboratory was able to obtain reliable results that imiquimod triggers type III cells to secrete 5HT, which then provides negative feedback to adjacent type II cells to shape the taste signals (Huang et al., 2007; Huang and $\mathrm{Wu}, 2016$ ).

A summary of the transmitter profile and taste signaling characteristics can be found in Roper and Chaudhari (2017). Serotonin-inhibitory signaling within taste buds, which shapes peripheral taste signals during the processing of gustatory information has been reported in human subjects (Heath et al., 2006) and rats (Jaber et al., 2014).
Specifically, the net effect of imiquimod $(10 \mu \mathrm{M})$, via initiated serotonergic inhibition within taste buds, reduced taste-evoked release of ATP (Huang and Wu, 2016). Considering the differences in methods and materials in these studies, the results are quite consistent. These results suggest the immune modulation of the processing of the gustatory information. Accordingly, these data suggest that the drug approved for the treatment of basal cell carcinoma, which causes taste disturbances by initiating the innate immune response (http://www.fda.gov/downloads/ Drugs/DevelopmentApprovalProcess/DevelopmentResources/ UCM252892.pdf; Kumar and Narang, 2011; Berking et al., 2014), alters taste signal transduction and transmission during processing of the gustatory stimulation. Parenthetically, this same resource reported that systemic absorption of imiquimod across the affected skin of human subjects generated mean peak serum concentrations ranging from 0.5 to $15 \mu \mathrm{M}$, indicating that the mechanism of the tasteimmune communication pathway may exist in the gustatory system. Figure 2 summarizes this postulated scenario in the schematic taste bud.

\section{Disruption of Taste Progenitor Cells Alters Taste Sensations}

Taste disturbance has also been reported in patients treated with vismodegib, another drug approved by the FDA for the treatment of basal-cell carcinoma (Berking et al., 2014; Yang et al., 2015; Frampton and Basset-Séguin, 2018). The notion

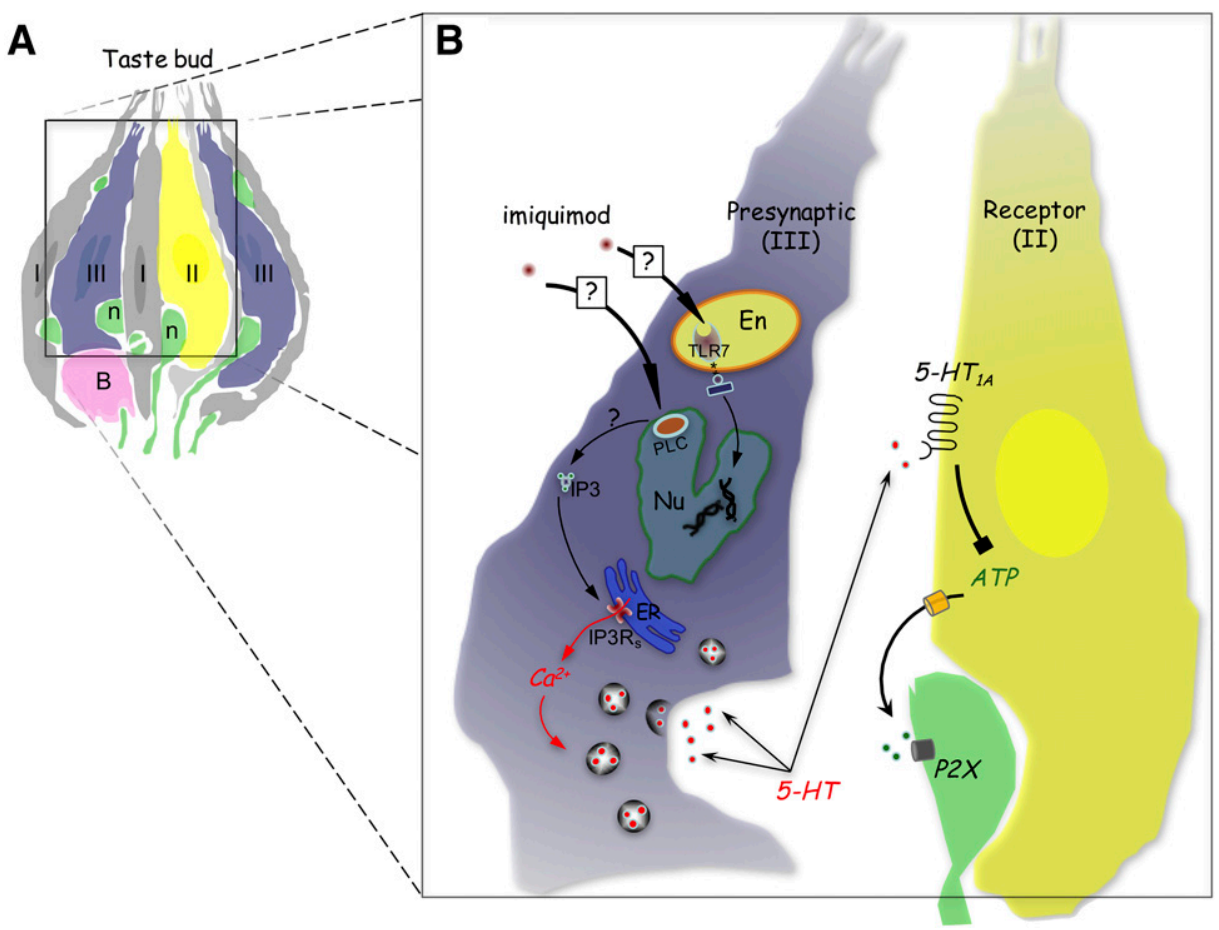

Fig. 2. Mammalian taste buds are located in the oral epithelium. Each taste bud is a compact cluster of about 100 cells that express different chemosensory transduction proteins, in part according to their functions. (A) Taste cells are divided into certain morphotypes, which are termed types I (I), II (II), III (III), and taste progenitor cells [also named basal cell (B)], originally on the basis of their histologic and ultrastructural characteristics. (B) Schematic diagram of a gustatory processing unit shows the pathways of imiquimod within taste buds. Recent findings support results of a previous study (Kim et al., 2011) that showed that imiquimod freely passed across the membrane of target cells and triggered certain PLC isoforms in the nucleus (Nu). Subsequently, activation of the downstream PLC cascade initiated generation of second messengers, such as inositol 1,4,5-trisphosphate (IP3) and, as a result, increased intracellular $\mathrm{Ca}^{2+}$ transients by activating IP3 receptors (IP3Rs) on the endoplasmic reticulum (ER). Conceivably, imiquimod elicits release of 5-HT from type III cells, thus acting as a transmitter that inhibits ATP secretion from type II cells and, theoretically, shapes the perceived intensity of some taste modalities. Alternatively, imiquimod may trigger innate immune reactions by activating TLR7 localized in the endosome (En) (Heil et al., 2004; Krieg and Vollmer, 2007; Kim et al., 2011; Hwang et al., 2014), resulting in production of proinflammatory cytokines, including IFN- $\alpha$ and TNF- $\alpha$ (Hemmi et al., 2002). In summary, new insights into the immune response explain contributions to taste dysfunctions by adversely affected taste transmission as well as by local effects in taste buds. Image reproduced with permission from AY Huang. 
that the alterations in human taste perceptions associated with vismodegib-induced taste disturbances are most probably due to the aberrant taste cell turnover and the integrity of taste bud functions would be straightforward. During embryogenesis and development, hedgehog controls epithelial and mesenchymal interactions in many tissues, and is a key regulator of cell growth and differentiation, respectively. Binding of hedgehog on its receptor patched homolog 1 (PTCH1) as a tumor suppressor prevents PTCH1-mediated inhibition of signaling by smoothened homolog (SMO). Initiation of SMO signaling results in the activation of downstream transcription factors, such as glioma-associated proteins, which control expression of hedgehog target genes (Amin et al., 2010). Thus, either inactivation of PTCH1 or constitutive activation of SMO results in substantial increase in the number of undifferentiated basal cells. Conceivably, total SMO inhibition by vismodegib, an aggressive blocker of smoothened homologue, is a therapeutic option in patients with basal cell carcinoma (Amin et al., 2010; Frampton and Basset-Séguin, 2018). Recently, Yang et al. (2015) identified the pathway responsible for taste changes among cancer patients treated with vismodegib. Using a mouse model to simulate the effect of vismodegib in treated patients, they found that blocking the hedgehog signaling pathway resulted in profound alternations in taste bud structure and function as well as gustatory neural transduction, thus facilitating our understanding of alterations in vismodegib-induced taste perceptions in cancer patients. Furthermore, Kumari et al. (2015) reported similar findings: In a mouse model, use of LDE225, an inhibitor of the hedgehog pathway, resulted in disruption of taste progenitor cells and alteration of taste perceptions.

In spite of the changes in taste signal transmission attributable to the effects of the immune response as a mechanism, imiquimod may also trigger PLC activation in the Golgi apparatus and nucleus (Cocco et al., 2001a,b; Suh et al., 2008; Grinberg et al., 2009), in which a variety of nuclear events occurs, including mRNA export, DNA repair, and gene transcription (Irvine 2003; Faenza et al., 2008, 2013). Indeed, in modern research systems, such as in vitro cell culture (Aisiku et al., 2011) and rodent models (Montaña et al., 2012), nuclear PLC $\beta$, known as the abundantly represented family of isozymes in nuclei, has been demonstrated to participate directly in controlling the cell cycle, in which there is a direct effect on G1 progression (Cocco et al., 2004; Faenza et al., 2013). Conceivably, acting as a potent cell autonomous inhibitor of oncogenic hedgehog signaling, which is crucial to taste cell turnover (Gruber et al., 2014; Castillo et al., 2014; Yang et al., 2015), imiquimod may also trigger local effects in taste buds. Hence, it is a feasible explanation that activating the immune responses causes either the interruption of taste cell turnover or the modulation of taste signal transmission, and thus the alterations in taste perceptions. However, without additional experimental results, the discussion is largely speculative.

\section{Conclusions}

Recent studies have provided evidence supporting the notion that the innate immune response alters taste sensations and provides a novel approach to the investigation of taste disturbances. (Wang et al., 2007, 2009; Cohn et al., 2010;
Feng et al., 2012; Berking et al., 2014; Yang et al., 2015; Frampton and Basset-Séguin, 2018). Furthermore, these results offer new insights into the mechanisms underlying the therapeutic effects of imiquimod on taste disturbances at pharmacologic doses (micromolar and higher) and, thus, as a taste sensation inhibitor.

This review has also highlighted the feasibility of a novel area of taste dysfunctions that has the potential to enhance health-related research. The characterization of local transmitters released from taste cells themselves and their aberrant effects caused by inflammation in the taste bud is essential not only for basic understanding of gustatory afferent excitation but also for potential clinical applications. These include development of taste modifiers for potential use in the management of obesity (Overberg et al., 2012), compliance in taking medications (particularly in pediatrics), and pharmaceutical development in the context of diminished taste sensation or ageusia related to age (Mistretta, 1984) or chemotherapy (Bernhardson et al., 2008; Pribitkin et al., 2003; Yamashita et al., 2006).

\section{Acknowledgments}

The author would like to acknowledge Cell Symposia and their conference "Neuro-Immune Axis: Reciprocal Regulation in Development, Health, and Disease" at which this work was presented.

\section{Authorship Contributions}

Wrote or contributed to the writing of the manuscript: Huang.

\section{References}

Aisiku O, Dowal L, and Scarlata S (2011) Protein kinase C phosphorylation of PLC $\beta 1$ regulates its cellular localization. Arch Biochem Biophys 509:186-190.

Akira S and Takeda K (2004) Toll-like receptor signalling. Nat Rev Immunol 4: 499-511.

Amin SH, Tibes R, Kim JE, and Hybarger CP (2010) Hedgehog antagonist GDC-0449 is effective in the treatment of advanced basal cell carcinoma. Laryngoscope 120: 2456-2459.

Bartel DL, Sullivan SL, Lavoie EG, Sévigny J, and Finger TE (2006) Nucleoside triphosphate diphosphohydrolase-2 is the ecto-ATPase of type I cells in taste buds. J Comp Neurol 497:1-12.

Berking C, Hauschild A, Kölbl O, Mast G, and Gutzmer R (2014) Basal cell carcinoma-treatments for the commonest skin cancer. Dtsch Arztebl Int 111: 389-395.

Bernhardson B-M, Tishelman C, and Rutqvist LE (2008) Self-reported taste and smell changes during cancer chemotherapy. Support Care Cancer 16:275-283.

Brikos C and O'Neill LA (2008) Signalling of toll-like receptors. Handb Exp Pharmacol 183:21-50.

Castillo D, Seidel K, Salcedo E, Ahn C, de Sauvage FJ, Klein OD, and Barlow LA (2014) Induction of ectopic taste buds by SHH reveals the competency and plasticity of adult lingual epithelium. Development 141:2993-3002.

Chandrashekar J, Yarmolinsky D, von Buchholtz L, Oka Y, Sly W, Ryba NJ, and Zuker CS (2009) The taste of carbonation. Science 326:443-445.

Chang RB, Waters H, and Liman ER (2010) A proton current drives action potentials in genetically identified sour taste cells. Proc Natl Acad Sci USA 107:22320-22325.

Chaudhari N, Pereira E, and Roper SD (2009) Taste receptors for umami: the case for multiple receptors. Am J Clin Nutr 90:738S-742S.

Chaudhari N and Roper SD (2010) The cell biology of taste. J Cell Biol 190:285-296.

Clapp TR, Medler KF, Damak S, Margolskee RF, and Kinnamon SC (2006) Mouse taste cells with G protein-coupled taste receptors lack voltage-gated calcium channels and SNAP-25. BMC Biol 4:7.

Cocco L, Capitani S, Maraldi NM, Martelli AM, Mazzotti G, and Manzoli FA (2004) Significance of nuclear phospholipase C signaling through type 1 IGF receptor. $J$ Endocrinol Invest 27 (6 Suppl):143-145.

Cocco L, Martelli AM, Barnabei O, and Manzoli FA (2001a) Nuclear inositol lipid signaling. Adv Enzyme Regul 41:361-384.

Cocco L, Martelli AM, Gilmour RS, Rhee SG, and Manzoli FA (2001b) Nuclear phospholipase $\mathrm{C}$ and signaling. Biochim Biophys Acta 1530:1-14.

Cohn ZJ, Kim A, Huang L, Brand J, and Wang H (2010) Lipopolysaccharide-induced inflammation attenuates taste progenitor cell proliferation and shortens the life span of taste bud cells. BMC Neurosci 11:72.

Cullen MM and Leopold DA (1999) Disorders of smell and taste. Med Clin North Am 83:57-74.

Dahl MV (2000) Imiquimod: an immune response modifier. J Am Acad Dermatol 43: S1-S5.

de Araujo IE, Oliveira-Maia AJ, Sotnikova TD, Gainetdinov RR, Caron MG, Nicolelis MA, and Simon SA (2008) Food reward in the absence of taste receptor signaling. Neuron 57:930-941. 
DeFazio RA, Dvoryanchikov G, Maruyama Y, Kim JW, Pereira E, Roper SD, and Chaudhari N (2006) Separate populations of receptor cells and presynaptic cells in mouse taste buds. $J$ Neurosci 26:3971-3980.

Delay ER, Hernandez NP, Bromley K, and Margolskee RF (2006) Sucrose and monosodium glutamate taste thresholds and discrimination ability of T1R3 knockout mice. Chem Senses 31:351-357.

Deshpande DA, Wang WCH, McIlmoyle EL, Robinett KS, Schillinger RM, An SS, Sham JS, and Liggett SB (2010) Bitter taste receptors on airway smooth muscle bronchodilate by localized calcium signaling and reverse obstruction. Nat Med 16 1299-1304.

Devantier HR, Long DJ, Brennan FX, Carlucci SA, Hendrix C, Bryant RW, Salemme FR, and Palmer RK (2008) Quantitative assessment of TRPM5-dependent oral aversiveness of pharmaceuticals using a mouse brief-access taste aversion assay. Behav Pharmacol 19:673-682.

Dvoryanchikov G, Huang YA, Barro-Soria R, Chaudhari N, and Roper SD (2011) GABA, its receptors, and GABAergic inhibition in mouse taste buds. J Neurosci $\mathbf{3 1}$ 5782-5791.

Dvoryanchikov G, Sinclair MS, Perea-Martinez I, Wang T, and Chaudhari N (2009) Inward rectifier channel, $\mathrm{ROMK}$ is localized to the apical tips of glial-like cells in mouse taste buds. J Comp Neurol 517:1-14.

Eyzaguirre C (2007) Electric synapses in the carotid body-nerve complex. Respir Physiol Neurobiol 157:116-122.

Faenza I, Bregoli L, Ramazzotti G, Gaboardi G, Follo MY, Mongiorgi S, Billi AM Manzoli L, Martelli AM, and Cocco L (2008) Nuclear phospholipase C beta1 and cellular differentiation. Front Biosci 13:2452-2463.

Faenza I, Fiume R, Piazzi M, Colantoni A, and Cocco L (2013) Nuclear inositide specific phospholipase C signalling - interactions and activity. FEBS $J \mathbf{2 8 0}$ $6311-6321$

Feng P, Chai J, Zhou M, Simon N, Huang L, and Wang H (2014) Interleukin-10 is produced by a specific subset of taste receptor cells and critical for maintaining structural integrity of mouse taste buds. $J$ Neurosci 34:2689-2701.

Feng P, Jyotaki M, Kim A, Chai J, Simon N, Zhou M, Bachmanov AA, Huang L, and Wang $H$ (2015) Regulation of bitter taste responses by tumor necrosis factor. Brain Behav Immun 49:32-42.

Feng P, Zhao H, Chai J, Huang L, and Wang H (2012) Expression and secretion of TNF- $\alpha$ in mouse taste buds: a novel function of a specific subset of type II taste cells. PLoS One 7:e43140.

Finger TE, Danilova V, Barrows J, Bartel DL, Vigers AJ, Stone L, Hellekant G, and Kinnamon SC (2005) ATP signaling is crucial for communication from taste buds to gustatory nerves. Science 310:1495-1499.

Frampton JE and Basset-Séguin N (2018) Vismodegib: a review in advanced basal cell carcinoma. Drugs 78:1145-1156.

Gomez FE, Cassís-Nosthas L, Morales-de-León JC, and Bourges H (2004) Detection and recognition thresholds to the 4 basic tastes in Mexican patients with primary Sjögren's syndrome. Eur J Clin Nutr 58:629-636.

Goodspeed RB, Gent JF, and Catalanotto FA (1987) Chemosensory dysfunction. Clinical evaluation results from a taste and smell clinic. Postgrad Med 81:251-257, 260 .

Graham CS, Graham BG, Bartlett JA, Heald AE, and Schiffman SS (1995) Taste and smell losses in HIV infected patients. Physiol Behav 58:287-293.

Grinberg S, Hasko G, Wu D, and Leibovich SJ (2009) Suppression of PLCbeta2 by endotoxin plays a role in the adenosine $\mathrm{A}(2 \mathrm{~A})$ receptor-mediated switch of macrophages from an inflammatory to an angiogenic phenotype. Am $J$ Pathol 175 2439-2453.

Gruber W, Frischauf AM, and Aberger F (2014) An old friend with new skills: imiquimod as novel inhibitor of Hedgehog signaling in basal cell carcinoma. Oncoscience 1:567-573.

Heath TP, Melichar JK, Nutt DJ, and Donaldson LF (2006) Human taste thresholds are modulated by serotonin and noradrenaline. $J$ Neurosci 26:12664-12671.

Heil F, Ahmad-Nejad P, Hemmi H, Hochrein H, Ampenberger F, Gellert T, Dietrich H, Lipford G, Takeda K, Akira S, et al. (2003) The Toll-like receptor 7 (TLR7) specific stimulus loxoribine uncovers a strong relationship within the TLR7, 8 and 9 subfamily. Eur J Immunol 33:2987-2997.

Heil F, Hemmi H, Hochrein H, Ampenberger F, Kirschning C, Akira S, Lipford G, Wagner H, and Bauer S (2004) Species-specific recognition of single-stranded RNA via toll-like receptor 7 and 8 . Science 303:1526-1529.

Helley MP, Abate W, Jackson SK, Bennett JH, and Thompson SW (2015) The expression of Toll-like receptor 4,7 and co-receptors in neurochemical subpopulations of rat trigeminal ganglion sensory neurons. Neuroscience 310:686-698.

Hemmi H, Kaisho T, Takeuchi O, Sato S, Sanjo H, Hoshino K, Horiuchi T, Tomizawa $\mathrm{H}$, Takeda K, and Akira S (2002) Small anti-viral compounds activate immune cells via the TLR7 MyD88-dependent signaling pathway. Nat Immunol 3:196-200.

Henkin RI, Larson AL, and Powell RD (1975) Hypogeusia, dysgeusia, hyposmia, and dysosmia following influenza-like infection. Ann Otol Rhinol Laryngol 84 $672-682$.

Henkin RI, Talal N, Larson AL, and Mattern CF (1972) Abnormalities of taste and smell in Sjogren's syndrome. Ann Intern Med 76:375-383

Herness S and Zhao FL (2009) The neuropeptides CCK and NPY and the changing view of cell-to-cell communication in the taste bud. Physiol Behav 97:581-591.

Hisatsune C, Yasumatsu K, Takahashi-Iwanaga H, Ogawa N, Kuroda Y, Yoshida R, Ninomiya Y, and Mikoshiba K (2007) Abnormal taste perception in mice lacking the type 3 inositol 1,4,5-trisphosphate receptor. J Biol Chem 282 $37225-37231$

Huang AL, Chen X, Hoon MA, Chandrashekar J, Guo W, Tränkner D, Ryba NJ, and Zuker CS (2006) The cells and logic for mammalian sour taste detection. Nature 442:934-938.

Huang AY and Wu SY (2015) Calcitonin gene-related peptide reduces taste-evoked ATP secretion from mouse taste buds. J Neurosci 35:12714-12724.

Huang AY and Wu SY (2016) The effect of imiquimod on taste bud calcium transients and transmitter secretion. Br J Pharmacol 173:3121-3133.
Huang AY and Wu SY (2018) Substance P as a putative efferent transmitter mediates GABAergic inhibition in mouse taste buds. $\mathrm{Br} J$ Pharmacol 175 1039-1053.

Huang YJ, Maruyama Y, Dvoryanchikov G, Pereira E, Chaudhari N, and Roper SD (2007) The role of pannexin 1 hemichannels in ATP release and cell-cell communication in mouse taste buds. Proc Natl Acad Sci USA 104:6436-6441.

Huang YA, Dando R, and Roper SD (2009) Autocrine and paracrine roles for ATP and serotonin in mouse taste buds. $J$ Neurosci 29:13909-13918.

Huang YA, Maruyama Y, and Roper SD (2008a) Norepinephrine is coreleased with serotonin in mouse taste buds. J Neurosci 28:13088-13093.

Huang YA, Maruyama Y, Stimac R, and Roper SD (2008b) Presynaptic (Type III) cells in mouse taste buds sense sour (acid) taste. J Physiol 586:2903-2912.

Huang YA, Pereira E, and Roper SD (2011a) Acid stimulation (sour taste) elicits GABA and serotonin release from mouse taste cells. PLoS One 6:e25471.

Huang YA and Roper SD (2010) Intracellular $\mathrm{Ca}(2+)$ and TRPM5-mediated membrane depolarization produce ATP secretion from taste receptor cells. J Physiol 588:2343-2350

Huang YA, Stone LM, Pereira E, Yang R, Kinnamon JC, Dvoryanchikov G, Chaudhari N, Finger TE, Kinnamon SC, and Roper SD (2011b) Knocking out P2X receptors reduces transmitter secretion in taste buds. $J$ Neurosci 31:13654-13661.

Hwang H, Min H, Kim D, Yu SW, Jung SJ, Choi SY, and Lee SJ (2014) Imiquimod induces a Toll-like receptor 7-independent increase in intracellular calcium via IP(3) receptor activation. Biochem Biophys Res Commun 450:875-879.

Imbertson LM, Beaurline JM, Couture AM, Gibson SJ, Smith RM, Miller RL, Reiter MJ, Wagner TL, and Tomai MA (1998) Cytokine induction in hairless mouse and rat skin after topical application of the immune response modifiers imiquimod and S-28463. J Invest Dermatol 110:734-739.

Irvine RF (2003) Nuclear lipid signalling. Nat Rev Mol Cell Biol 4:349-360.

Ishida Y, Ugawa S, Ueda T, Murakami S, and Shimada S (2002) Vanilloid receptor subtype-1 (VR1) is specifically localized to taste papillae. Brain Res Mol Brain Res 107:17-22.

Ishimaru Y and Matsunami H (2009) Transient receptor potential (TRP) channels and taste sensation. $J$ Dent Res 88:212-218.

Jaber L, Zhao FL, Kolli T, and Herness S (2014) A physiologic role for serotonergic transmission in adult rat taste buds. PLoS One 9:e112152.

Kapaun CL and Dando R (2017) Deconvoluting physical and chemical heat: temperature and spiciness influence flavor differently. Physiol Behav 170:54-61.

Kawai T and Akira S (2007) Signaling to NF-kappaB by toll-like receptors. Trends Mol Med 13:460-469.

Kim A, Feng P, Ohkuri T, Sauers D, Cohn ZJ, Chai J, Nelson T, Bachmanov AA, Huang L, and Wang H (2012) Defects in the peripheral taste structure and function in the MRL/lpr mouse model of autoimmune disease. PLoS One 7:e35588.

Kim SJ, Park GH, Kim D, Lee J, Min H, Wall E, Lee CJ, Simon MI, Lee SJ, and Han SK (2011) Analysis of cellular and behavioral responses to imiquimod reveals a unique itch pathway in transient receptor potential vanilloid 1 (TRPV1)expressing neurons. Proc Natl Acad Sci USA 108:3371-3376.

Kinnamon SC and Vandenbeuch A (2009) Receptors and transduction of umami taste stimuli. Ann N Y Acad Sci 1170:55-59.

Krieg AM and Vollmer J (2007) Toll-like receptors 7, 8, and 9: linking innate immunity to autoimmunity. Immunol Rev 220:251-269.

Kumar B and Narang T (2011) Local and systemic adverse effects to topical imiquimod due to systemic immune stimulation. Sex Transm Infect 87:432.

Kumari A, Ermilov AN, Allen BL, Bradley RM, Dlugosz AA, and Mistretta CM (2015) Hedgehog pathway blockade with the cancer drug LDE225 disrupts taste organs and taste sensation. $J$ Neurophysiol 113:1034-1040.

Lee J, Chuang TH, Redecke V, She L, Pitha PM, Carson DA, Raz E, and Cottam HB (2003) Molecular basis for the immunostimulatory activity of guanine nucleoside analogs: activation of Toll-like receptor 7. Proc Natl Acad Sci USA $\mathbf{1 0 0}$ 6646-6651.

Long DJ, Devantier HR, Brennan FX, Bryant RW, Salemme FR, and Palmer RK (2010) Pharmacologic antagonism of the oral aversive taste-directed response to capsaicin in a mouse brief access taste aversion assay. J Pharmacol Exp Ther 332: $525-530$

Medler KF, Margolskee RF, and Kinnamon SC (2003) Electrophysiological characterization of voltage-gated currents in defined taste cell types of mice. $J$ Neurosci 23:2608-2617.

Miller RL, Gerster JF, Owens ML, Slade HB, and Tomai MA (1999) Imiquimod applied topically: a novel immune response modifier and new class of drug. Int J Immunopharmacol 21:1-14.

Mistretta CM (1984) Aging effects on anatomy and neurophysiology of taste and smell. Gerodontology 3:131-136.

Montaña M, García del Caño G, López de Jesús M, González-Burguera I, Echeazarra L, Barrondo S, and Sallés J (2012) Cellular neurochemical characterization and subcellular localization of phospholipase C $\beta 1$ in rat brain. Neuroscience 222: 239-268.

Murtaza B, Hichami A, Khan AS, Ghiringhelli F, and Khan NA (2017) Alteration in taste perception in cancer: causes and strategies of treatment. Front Physiol 8:134 Nishiya T, Kajita E, Miwa S, and Defranco AL (2005) TLR3 and TLR7 are targeted to the same intracellular compartments by distinct regulatory elements. $J$ Biol Chem 280:37107-37117.

Nurse CA (2005) Neurotransmission and neuromodulation in the chemosensory carotid body. Auton Neurosci 120:1-9.

Oda $\mathrm{K}$ and Kitano $\mathrm{H}$ (2006) A comprehensive map of the toll-like receptor signaling network. Mol Syst Biol 2.2006.0015.

Ohkuri T, Yasumatsu K, Horio N, Jyotaki M, Margolskee RF, and Ninomiya Y (2009) Multiple sweet receptors and transduction pathways revealed in knockout mice by temperature dependence and gurmarin sensitivity. Am J Physiol Regul Integr Comp Physiol 296:R960-R971.

Oka Y, Butnaru M, von Buchholtz L, Ryba NJ, and Zuker CS (2013) High salt recruits aversive taste pathways. Nature 494:472-475. 
Overberg J, Hummel T, Krude H, and Wiegand S (2012) Differences in taste sensitivity between obese and non-obese children and adolescents. Arch Dis Child 97: 1048-1052.

Palacios-Prado N, Sonntag S, Skeberdis VA, Willecke K, and Bukauskas FF (2009) Gating, permselectivity and $\mathrm{pH}$-dependent modulation of channels formed by connexin57, a major connexin of horizontal cells in the mouse retina. J Physiol 587: 3251-3269.

PDR Staff (2010) PDR guide to drug interactions, side effect, and indication 2010, 64 ed, John Wiley and Sons, Hoboken, NJ.

Pribitkin E, Rosenthal MD, and Cowart BJ (2003) Prevalence and causes of severe taste loss in a chemosensory clinic population. Ann Otol Rhinol Laryngol 112 971-978.

Quan N and Banks WA (2007) Brain-immune communication pathways. Brain Behav Immun 21:727-735.

Rogers KL, Stinnakre J, Agulhon C, Jublot D, Shorte SL, Kremer EJ, and Brûlet P (2005) Visualization of local $\mathrm{Ca} 2+$ dynamics with genetically encoded bioluminescent reporters. Eur J Neurosci 21:597-610.

Romanov RA, Rogachevskaja OA, Bystrova MF, Jiang P, Margolskee RF, and Kolesnikov SS (2007) Afferent neurotransmission mediated by hemichannels in mammalian taste cells. EMBO J 26:657-667.

Roper SD (2014) TRPs in taste and chemesthesis. Handb Exp Pharmacol 223: 827-871.

Roper SD and Chaudhari N (2017) Taste buds: cells, signals and synapses. Nat Rev Neurosci 18:485-497.

Schön M, Bong AB, Drewniok C, Herz J, Geilen CC, Reifenberger J, Benninghoff B, Slade HB, Gollnick H, and Schön MP (2003) Tumor-selective induction of apoptosis and the small-molecule immune response modifier imiquimod. J Natl Cancer Inst 95:1138-1149.

Shi L, He L, Sarvepalli P, and McCluskey LP (2012) Functional role for interleukin-1 in the injured peripheral taste system. J Neurosci Res 90:816-830.

Simon SA, Liu L, and Erickson RP (2003) Neuropeptides modulate rat chorda tympani responses. Am J Physiol Regul Integr Comp Physiol 284:R1494-R1505.

Suh PG, Park JI, Manzoli L, Cocco L, Peak JC, Katan M, Fukami K, Kataoka T, Yun S, and Ryu SH (2008) Multiple roles of phosphoinositide-specific phospholipase C isozymes. BMB Rep 41:415-434.

Talavera K, Yasumatsu K, Yoshida R, Margolskee RF, Voets T, Ninomiya Y, and Nilius B (2008) The taste transduction channel TRPM5 is a locus for bittersweet taste interactions. FASEB $J$ 22:1343-1355.

Taruno A, Vingtdeux V, Ohmoto M, Ma Z, Dvoryanchikov G, Li A, Adrien L, Zhao H, Leung S, Abernethy M, et al. (2013) CALHM1 ion channel mediates purinergic neurotransmission of sweet, bitter and umami tastes. Nature 495:223-226.

Tomchik SM, Berg S, Kim JW, Chaudhari N, and Roper SD (2007) Breadth of tuning and taste coding in mammalian taste buds. J Neurosci 27:10840-10848.

Treesukosol Y, Blonde GD, and Spector AC (2009) T1R2 and T1R3 subunits are individually unnecessary for normal affective licking responses to Polycose: implications for saccharide taste receptors in mice. Am J Physiol Regul Integr Comp Physiol 296:R855-R865.

Vandenbeuch A, Clapp TR, and Kinnamon SC (2008) Amiloride-sensitive channels in type I fungiform taste cells in mouse. BMC Neurosci 9:1.

Vandenbeuch A, Larson ED, Anderson CB, Smith SA, Ford AP, Finger TE, and Kinnamon SC (2015) Postsynaptic P2X3-containing receptors in gustatory nerve fibres mediate responses to all taste qualities in mice. J Physiol 593:1113-1125.

Wang H, Zhou M, Brand J, and Huang L (2007) Inflammation activates the interferon signaling pathways in taste bud cells. J Neurosci 27:10703-10713.

Wang H, Zhou M, Brand J, and Huang L (2009) Inflammation and taste disorders: mechanisms in taste buds. Ann N Y Acad Sci 1170:596-603.

Wang Y, Erickson RP, and Simon SA (1995) Modulation of rat chorda tympani nerve activity by lingual nerve stimulation. $J$ Neurophysiol 73:1468-1483.

Weiffenbach JM, Schwartz LK, Atkinson JC, and Fox PC (1995) Taste performance in Sjogren's syndrome. Physiol Behav 57:89-96.

Wurm A, Lipp S, Pannicke T, Linnertz R, Krügel U, Schulz A, Färber K, Zahn D, Grosse J, Wiedemann P, et al. (2010) Endogenous purinergic signaling is required for osmotic volume regulation of retinal glial cells. J Neurochem 112:1261-1272.

Xu H, Staszewski L, Tang H, Adler E, Zoller M, and Li X (2004) Different functiona roles of T1R subunits in the heteromeric taste receptors. Proc Natl Acad Sci USA 101:14258-14263.

Xu J, Tse FW, and Tse A (2003) ATP triggers intracellular Ca2+ release in type II cells of the rat carotid body. $J$ Physiol 549:739-747.

Yamashita H, Nakagawa K, Tago M, Nakamura N, Shiraishi K, Eda M, Nakata H, Nagamatsu N, Yokoyama R, Onimura M, et al. (2006) Taste dysfunction in patients receiving radiotherapy. Head Neck 28:508-516.

Yang H, Cong WN, Yoon JS, and Egan JM (2015) Vismodegib, an antagonist of hedgehog signaling, directly alters taste molecular signaling in taste buds. Cancer Med 4:245-252.

Yang R, Crowley HH, Rock ME, and Kinnamon JC (2000) Taste cells with synapses in rat circumvallate papillae display SNAP-25-like immunoreactivity. J Comp Neurol 424:205-215.

Yee CL, Yang R, Böttger B, Finger TE, and Kinnamon JC (2001) “Type III” cells of rat taste buds: immunohistochemical and ultrastructural studies of neuron-specific enolase, protein gene product 9.5, and serotonin. J Comp Neurol 440:97-108.

Yoshida R, Ohkuri T, Jyotaki M, Yasuo T, Horio N, Yasumatsu K, Sanematsu K, Shigemura N, Yamamoto T, Margolskee RF, et al. (2010) Endocannabinoids selectively enhance sweet taste. Proc Natl Acad Sci USA 107:935-939.

Address correspondence to: Dr. Anthony Y. Huang, Department of Anatomy, 1135 Lincoln Drive, Rm 2069 Life Science III BLDG, Southern Illinois University School of Medicine, Carbondale, IL 62901. E-mail: ahuang@ siumed.edu 